\title{
ELECTRODES MODIFIED BY П STACKING OF METALLIC PHTHALOCYANINES AND ITS ELECTROCATALYTIC ACTIVITY ON NITRITE OXIDATION
}

\author{
NATALIA NAVARRETE, CAMILA CANALES, RODRIGO DEL RIO AND GALO RAMÍREZ*
}

\author{
Facultad de Química, Departamento de Química Inorgánica, Pontificia Universidad Católica de Chile \\ Av.Vicuña Mackenna, 4860, Macul, Santiago, Chile
}

(Received: June 12, 2013 - Accepted: August 26, 2013)

\begin{abstract}
In this work, it proposed the developing of a new material, a modified electrode with metallic phthalocyanines stacking columns, MxPc $(\mathrm{Mx}=\mathrm{Co}, \mathrm{Fe}$ and $\mathrm{Ni}$ ), assembled by $\pi$ interactions, which have a behavior as a supramolecular system. These electrodes showed an important electrocatalytic activity against nitrite oxidation, compared to the same complexes monomer multilayers adsorbed on the electrode (M-MxPc). It is proposed two new obtaining methods of these systems, S1-MxPc, where the complexes would form a column and would be coordinated with the surface electrode through a covalent bond of 4-aminopyridine (4-AP), and S2-MxPc, where the own functional groups of glassy carbon (GC) would be the covalent unions able to coordinate the complexes and the columns formation. These covalent unions between the electrode surface and phthalocyanines, would give a directional stacking, and therefore, would modify both its electrocatalytical activity and its electrical features.

It was also studied the dependence between the activity and the complex central metal (Co, Fe and $\mathrm{Ni})$, finding a great dependence between them. It was found that the S2-MxPc modified electrodes were more stables and actives. The higher activity was found on S2-CoPc, which also performs a linear response. This last feature it is seen on a calibration curve with a large range of concentrations. It is important to notice that there is actually no relative information about the behavior of the new electrodes proposed on this work.
\end{abstract}

Keywords: Supramolecular; phthalocyanines; Modified electrode; Nitrite Electro-oxidation.

\section{INTRODUCTION}

The modified electrodes with macrocyclic complexes have been widely studied because of its high activity on interesting reactions. Recent investigations on electrocatalysis field, electrode modifications with macrocyclic complexes such as porphyrins or phthalocyanines with metal center $(\mathrm{Co}, \mathrm{Cu}, \mathrm{Ni})$, have a great versatility due to its electrochemical activity as electrocatalysts, detectors and sensors in a huge variety of reactions [1-3].

It was also found that the stability and activity of these systems change according to the modification method. For example, the most common modification is the one where the electrode surface is modified with multilayers of monomers of the complex, by adsorption methods or physic-adsorption, being the most common the ones that implies the immersion of the electrode on the dissolvent with the predetermined complex. This procedure allows the formation of multilayers of monomers on the electrode surface [4]

Parallel to this, the supramolecular chemistry is a multidisciplinary field focused on the study and use of molecular assemblies unified through noncovalents interactions, such as hydrogen bond, Van der Waals forces and $\pi-\pi$ interactions [5].

In general, the supramolecular systems formation is a spontaneous process that has no requirement of high activation energies. The loss of the entropy is widely reestablished by the negative variations in the enthalpy due to the formation of a great amount of non-covalent bonds [6]

There is no doubt that the most interesting feature on a supramolecular system is its behavior, which is different compared to its parts individually, even when the complex that is used is the same one.

This change is due to its own nature; the supramolecular interactions are directional, where the $\pi$ interactions that unify the complexes include an orbital overlapping and show conductivity through the stacking [6].

A precedent related to the properties changes, due to the variations of the interactions, is the study of a conductive system that is formed by overlapping of porphyrins complexes with supramolecular character. This overlapping is basically given by $\pi$ interactions and is modulated by a group of factors, where the most important are: the dissolvent, and the interactions of the ligands (steric effect).

Practically, there are no studies about modified electrodes with supramolecular systems of phthalocyanine complexes (Figure 1), which could work as electrocatalysts.

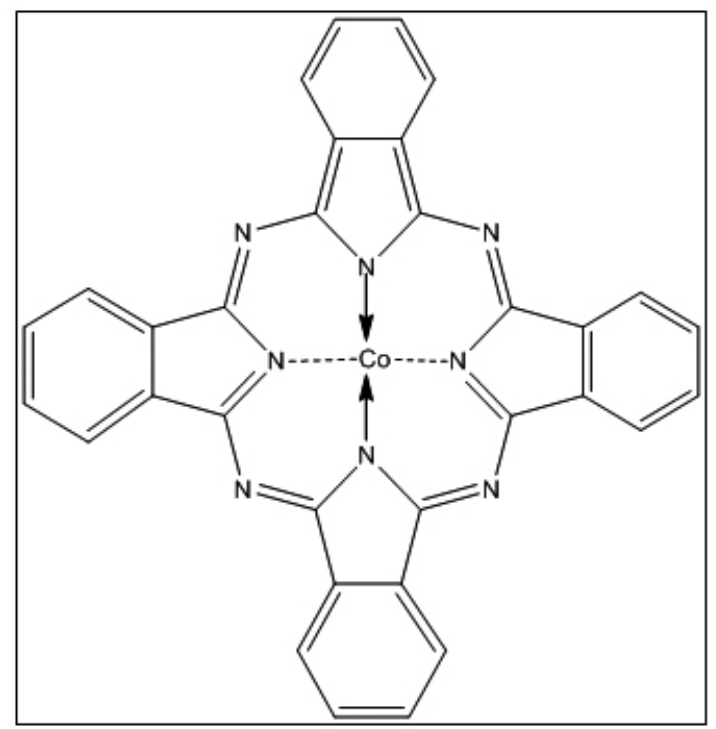

Figure 1. Structure of metallic phthalocyanines (MxPC). is show CoPC.

\section{Nitrite oxidation}

In the last decade, the study of nitrite has shown a great relevance, due to a lot of environmental and biological processes in which these are involved. Nitrite is also an active intermediate on nitrogen cycle [7]

The nitrites are usually used as fertilizers, so they have a high environmental impact on contamination of water sources, and they are added as preservers on food industry [8].

One of the main worries about nitrite is that this specie has an important role as a precursor on the formation of $\mathrm{N}$-nitrosamines, which are carcinogenic compounds that are found in nature $[8,9]$. For this reason, as a preventive way, the annual limit level set by ISP (Institute of Chilean Public Health) is $0.5 \mathrm{ppm}$ for nitrite and $40 \mathrm{ppm}$ for nitrate in potable water [10].

A variety of techniques have been published for determination of nitrite, for example, chromatography $[11,12]$, spectrophotometry $[12,13]$ and electrochemistry [14]. The electrochemical techniques offer advantages over another analytical methods, since they are faster, cheaper and more secure techniques. The electrochemical determination of nitrite can be done via either reduction or oxidation of it. 
The difference between these reactions is that the oxidation of nitrite has the advantage of being free of interferences of nitrate and oxygen molecules, which are the common limitations in the determination $[15,16]$.

The determination of this analite is hard on conventional electrodes, because the nitrite oxidation requires high potentials [17] and due to the facility of the electrode to get contaminated by the produced species during the electrochemical process [18]. Also, the electrochemical determination of nitrite is prone to the interference of another substances easily oxidables.

For this reason, the modifications of the electrode surfaces with appropriate catalysts, give the possibility to do the nitrite oxidation at low potentials.

\section{EXPERIMENTAL}

MxPc was purchased from Sigma-Aldrich. Tetrabutylammonium perchlorate (TBAP), monobasic and dibasic potassium phosphate (Sigma Aldrich), sodium nitrite, and $\mathrm{NaOH}$, (Merck) were analytical grade reagents. Deionized water was obtained from a Millipore-Q-system. Argon $\quad(99.99 \%$ pure) gas was purchased from AGA-Chile.

\section{Equipment}

Cyclic voltammetry studies were performed on a $\mathrm{CHI}$ instrument $620 \mathrm{C}$ potentiostat galvanostat.

The conventional three-electrode system consisted of a glassy carbon working electrode, $\mathrm{Ag} / \mathrm{AgCl}(3 \mathrm{M} \mathrm{KCl})$ reference electrode, and a platinum wire counter electrode.

\section{Preparation of modified electrode}

The glassy carbon electrode was polished to a mirror finish on a felt pad using alumina slurries $(3 \mathrm{~mm})$. The monomer-modified electrode was obtained by dispensing a drop of $1 \mathrm{mM} \mathrm{MxPc} / \mathrm{NaOH}(0.1 \mathrm{M})$ on the glassy carbon electrode surface (dry-drop method).

The S1-MxPc modified electrodes, were obtained by the reported method [19], which consists on an electrochemical step of oxidation, followed by a chemical step of reflux. The inclusion of the coupling covalent union of 4-AP is checked in front of a hydrogen evolution reaction. The S2-MxPc modified electrode, as the first one, has two steps, where the first stage consists on an oxidation at $+1.6 \mathrm{~V}$ vs $\mathrm{Ag} / \mathrm{AgCl}$, generating the functional groups on the electrode surface. As same as for S1-MxPc, the chemical step corresponds on a reflux process [19]. The modified electrodes were carefully rinsed with water to remove excess, electrolyte and finally with Milli-Q water. The modified electrode was stabilized in phosphate buffer by cycling the potential within the potential window at which nitrite oxidation is performed.

\section{RESULTS}

The electroreduction of nitrite was studied for systems, S1-MxPc, S2$\mathrm{MxPc}$, and $\mathrm{M}-\mathrm{MxPc}(\mathrm{Mx}=\mathrm{Co}, \mathrm{Ni}, \mathrm{Fe})$, on $\mathrm{pH} 11$ buffer and a $2 \mathrm{mM}$ nitrite concentration. Figures 2, 3 and 4, show the voltammetric profiles of all systems for nitrite oxidation. In all cases, it can be seen that the S2-MxPc modified system is the most active one, followed by the $\mathrm{S} 1-\mathrm{MxPc}$, which both yield an overpotential reductions, and a huge current increase. It is important to notice that the modified electrodes with monomer multilayers (M-MxPc) is the less active system, even showing a great diminution on the activity compared to the bare glassy carbon (GC), which can imply that in some way, the monomer multilayers block own active sites of GC, provoking an activity loss. This is also evidence about the difference and the importance of modification method, since when the same molecule $(\mathrm{MxPc})$ is arranged as columns, oriented by a covalent union (4-AP, for $\mathrm{S} 1-\mathrm{MxPc}$ case, and own GC functional groups for $\mathrm{S} 2 \mathrm{MxPc}$ case) would be determinant on the behavior for this reaction. For S2-MxPc system, the generated functional groups [20] would give order and different directionality in columns, giving different behavior to $\mathrm{S} 1-\mathrm{MxPc}$ system. This great activity increase given by S2-MxPc and S1-MxPc systems, would be coherent with the thought about how supramolecular systems are formed. This formation is based on a stacking of phthalocyanine complexes, united by $\pi$-interactions, oriented by a covalent union able to act as a unity, and so, as a totally different system compared to the monomer multilayers of the same complexes, physic-adsorbed on the surface. On the other side, the structural feature of the molecule forbid the polymerization (because it has no groups for polymerization on its structure), discarding that the activity amount be due to a conjugated system, based on a conductive polymer. So, the most probable accommodation of the S2-MxPc and S1-MxPc systems, would be conjugated systems, with a extended p-cloud, given by a distribution of the columns as happen in similar systems.

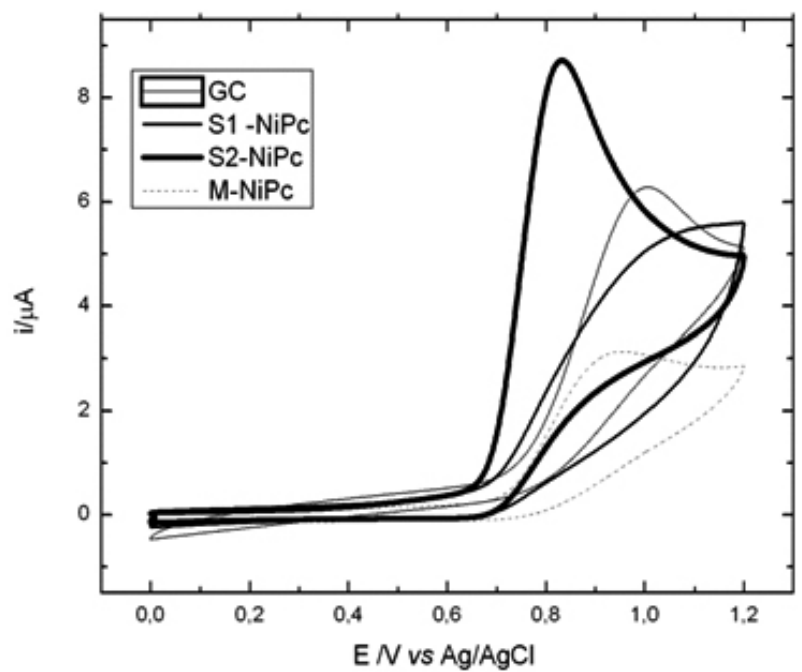

Figure 2. Voltammetric profile of S2-NiPc (thick solid line), S1-NiPc (thin solid line), M-NiPc (fine solid line) and bare GC (dashed line) toward nitrite oxidation ( $2 \mathrm{mM}$ nitrite in $\mathrm{pH} 11$ phosphate buffer solution), $0.1 \mathrm{~V} / \mathrm{s}$ (scan rate), purged with Ar.

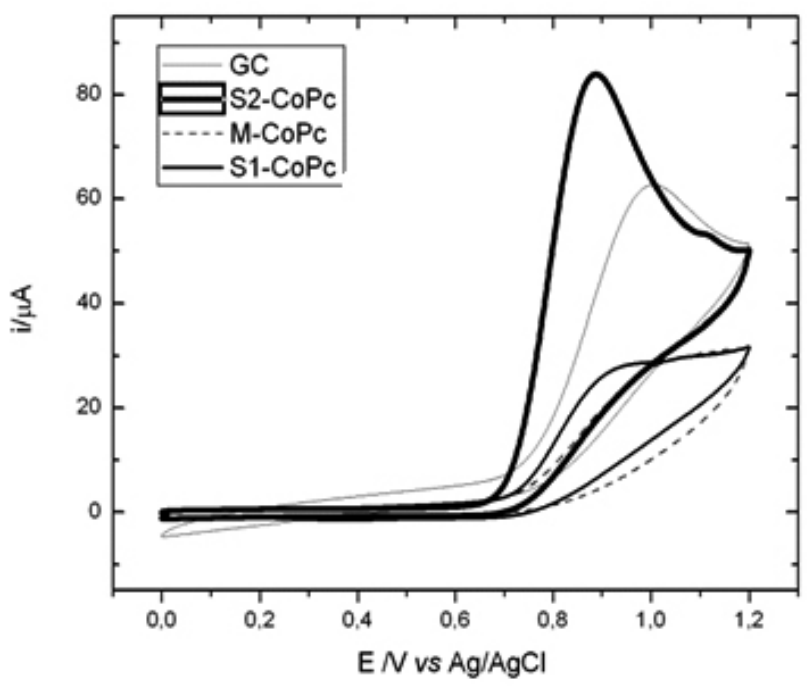

Figure 3. Voltammetric profile of S2-CoPc (thick solid line), S1-CoPc (thin solid line), M-CoPc (dashed line) and bare GC (fine solid line) toward nitrite oxidation ( $2 \mathrm{mM}$ nitrite in $\mathrm{pH} 11$ phosphate buffer solution), $0.1 \mathrm{~V} / \mathrm{s}$ (scan rate), purged with Ar.

\section{Central Metal Effect}

Figures 5 and 6 show votammetric profiles for S2-MxPc and S1-MxPc systems, respectively. In both cases, it is seen that the electrode that was modified with $\mathrm{CoPc}$ reaches the greater activity. For S1-MxPc system, it was observed that the electrodes modified with FePc and NiPc followed the electrode with $\mathrm{CoPc}$ in terms of activity. The voltammetric response for NiPc shows a lower active electrode than the bare glassy carbon electrode (it is also seen in Figure 3), as well as happens with M-MxPc modification. As it was mentioned before, this phenomenon would indicate that there is an own activity blocking, which suggest that this kind of modification would have a similar distribution compared to the one that was obtained with monomer multilayers. In Figure 5 , it is seen that for $\mathrm{S} 2-\mathrm{MxPc}$ system, the NiPc and FePc modified electrodes follow the one that was modified with CoPc in terms of activity. Unlike S1$\mathrm{MxPc}$ system, in this case, the responses show more similarity and always give more active systems that the monomer multilayers. From these results, 
it is also deducted that both systems are different. Actually, these systems show different activity compared to the system with MxPc modification, which implies that the electrocatalytical answer depends on the proposed modification method, being, in general, the S1-MxPc modification the most active one. As it was mentioned, in both cases, the most important experimental feature that is different from the monomer multilayers modification is the reflux procedure that is done before the covalent union inclusion, even if it is created by oxidation $(\mathrm{S} 2-\mathrm{MxPc})$ or electrochemically $(\mathrm{S} 2-\mathrm{MxPc})$. Probably, the reflux procedure allows the columns distribution in these complexes and the directional on those columns. This feature would be the one that makes the difference between both systems ( $\mathrm{S} 1-\mathrm{MxPc}$ and $\mathrm{S} 2-\mathrm{MxPc})$, where maybe the spatial distribution, or the amount and interaction on these columns would differ, giving different activity. Also, the first layer of complexes is coordinated to the covalent union by a free axial position of the central metal. For the S1$\mathrm{MxPc}$ case, this phenomenon is maybe very dependent on the metal type, unlike S2-MxPc, where the responses for nitrite oxidation are similar between them. Parallel to this, it is for sure that besides of what was described before, the metal has an important role on the nitrite oxidation mechanism, because for each system, each voltammetric profile differs when the metal is changed. For this reason, the metal for both complexes, $\mathrm{S} 1-\mathrm{MxPc}$ and $\mathrm{S} 2-\mathrm{MxPc}$, would have different chemical surrounding, and then, different electronic density, giving different activity as result. From Figures 5 and 6, it is seen that the most active system for nitrite oxidation is the S2-CoPc system, showing lower oxidation potentials, and higher current responses.

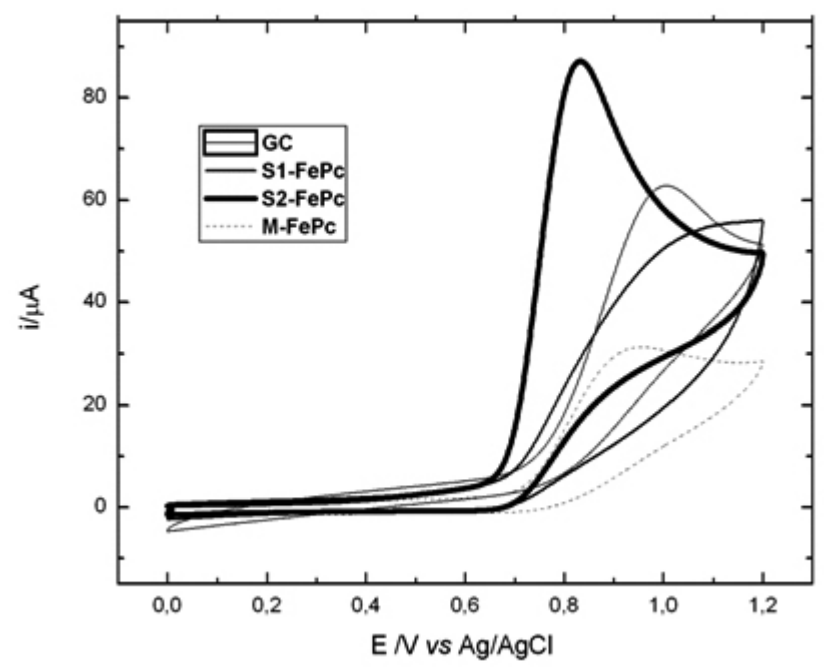

Figure 4. Voltammetric profile of $\mathrm{S} 2-\mathrm{FePc}$ (thick solid line), S1-FePc (thin solid line), M-FePc (dashed line) and bare GC (fine solid line) toward nitrite oxidation ( $2 \mathrm{mM}$ nitrite in $\mathrm{pH} 11$ phosphate buffer solution), $0.1 \mathrm{~V} / \mathrm{s}$ (scan rate), purged with Ar.

Considering that the $\mathrm{CoPc}$ modified electrodes were the most active systems, the stability in front of nitrite oxidation was studied. To determine this parameter, it was measured the first group of 20 cycles, and after this procedure, the system was bubbled with Argon by 10 minutes before doing the 20 cycles measurement again. Each measurement was done under the same experimental conditions.

Table 1 shows, with the biggest percentage, that the most stable system was the $\mathrm{S} 2-\mathrm{CoPc}$ one. Its stability allows us to suppose that this good response is a reason for being used as amperometrical sensor. Over again, it is seen the difference between both systems, S1-CoPc and S2-CoPc, where the best stability is shown by S2-CoPc system, which show the covalent union importance on the columns directionality and on the system stability.

However, both systems (S1-CoPc and S2-CoPc) are more stables than the monomer multilayers (M-CoPc).

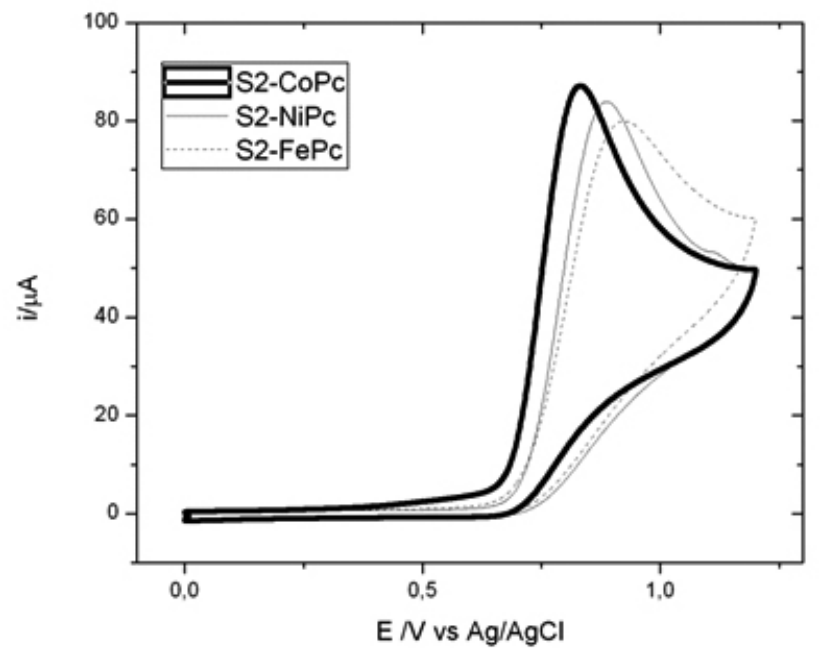

Figure 5. Voltammetric profile of S2-CoPc (thick solid line), S2-NiPc (thin solid line) and $\mathrm{S} 2-\mathrm{FePc}$ (dashed line), toward nitrite oxidation (2mM nitrite in $\mathrm{pH} 11$ phosphate buffer solution), $0.1 \mathrm{~V} / \mathrm{s}$ (scan rate), purged with Ar.

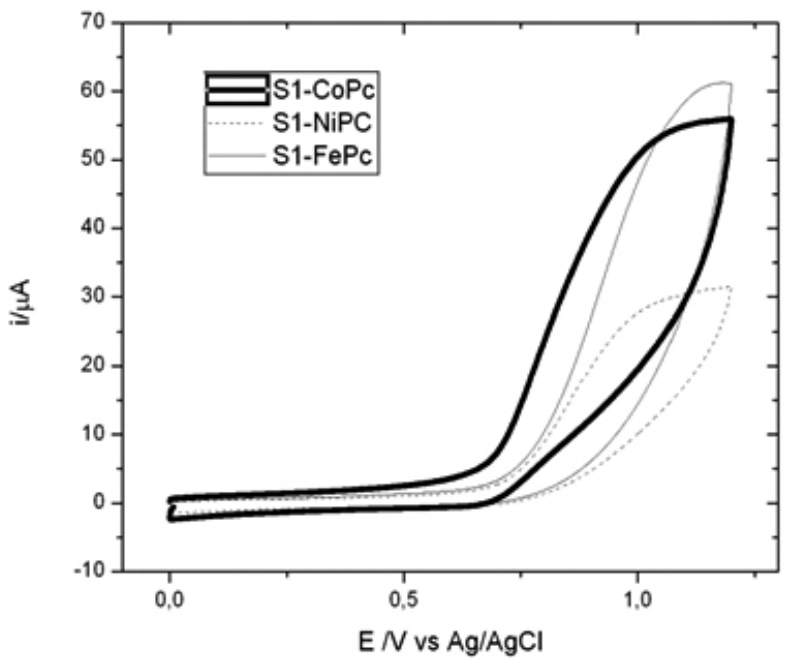

Figure 6. Voltammetric profile of S1-CoPc (thick solid line), S1-NiPc (dashed line), and $\mathrm{S} 1-\mathrm{FePc}$ (thin solid line), toward nitrite oxidation ( $2 \mathrm{mM}$ nitrite in $\mathrm{pH} 11$ phosphate buffer solution), 0.1V/s (scan rate), purged with Ar.

Table 1. Stability of CoPc modified electrodes, by number of cycles, toward nitrite oxidation ( $2 \mathrm{mM}$ nitrite in $\mathrm{pH} 11$ phosphate buffer solution), $0.1 \mathrm{~V} / \mathrm{s}$ (scan rate), Ar atmosphere.

\begin{tabular}{|c|c|c|c|c|}
\hline \multicolumn{2}{|c|}{} & $\begin{array}{c}\text { No of } \\
\text { cycles }\end{array}$ & $\mathbf{i} / \boldsymbol{\mu A}$ & $\begin{array}{c}\text { Stability } \\
\text { (percentage) }\end{array}$ \\
\hline \multicolumn{2}{|c|}{ S2-CoPc } & 20 & $6.74 \mathrm{E}-05$ & $100.0 \%$ \\
\hline \multicolumn{2}{|c|}{} & 40 & $6.70 \mathrm{E}-05$ & $99.4 \%$ \\
\hline \multicolumn{2}{|c|}{ S1-CoPc } & 60 & $6.69 \mathrm{E}-05$ & $99.3 \%$ \\
\hline \multicolumn{2}{|c|}{} & 20 & $7.98 \mathrm{E}-05$ & $100,0 \%$ \\
\hline \multicolumn{2}{|c|}{ m-CoPc } & 40 & $7.02 \mathrm{E}-05$ & $87.9 \%$ \\
\hline \multicolumn{2}{|l|}{} & 60 & $6.25 \mathrm{E}-05$ & $78.3 \%$ \\
\hline & & 40 & $7.71 \mathrm{E}-05$ & $100,0 \%$ \\
\hline
\end{tabular}


Figure 7 shows a calibration curve for S2-CoPc electrode, considering that it was the most active and stable obtained system. The linearity was shown in a range of concentrations of nitrite between $0.005 \mathrm{mM}$ and $2.0 \mathrm{mM}$. This last idea suggests that the system could act as a possible amperometrical sensor for nitrite.

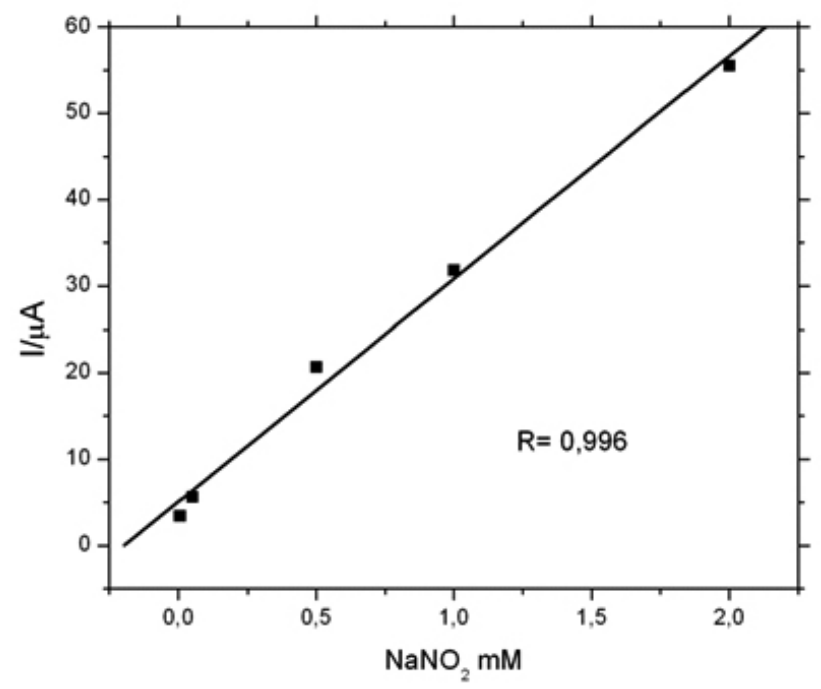

Figure 7. Plot of Ip vs. nitrite concentration (between $0.005 \mathrm{mM}$ and 2.0 $\mathrm{mM}$ ) for $\mathrm{S} 2-\mathrm{CoPc}$ at $\mathrm{pH} 11$, scan rate $0.1 \mathrm{~V} / \mathrm{s}$; purged with $\mathrm{Ar}$

\section{Electrochemical calculations}

The electrochemical calculations were made for S2-MxPc systems, due to their activity on nitrite oxidation. From $\log I$ vs $\log \mathrm{v}$ graphs and Ip vs v $\mathrm{v}^{0.5}$ (non shown) it is possible to conclude that the mechanism has a diffusion control [21].

Considering that the catalytic system has a behavior as a totally irreversible process with diffusion control, it is possibly to obtain the number of total electrons (n) that are involved in each reaction (Table 2) through equation 1.

$$
I p=\left(2.99 \times 10^{5}\right) n\left[(1-\alpha) n_{a}\right]^{1 / 2} \text { Co A Do }{ }^{1 / 2} v^{1 / 2}
$$

(Equation 1)

Where $\alpha$ is the electronic transfer coefficient, $\mathrm{n}$ represents the number of electrons that are involved on the slow step of the reaction, $\mathrm{D}\left(\mathrm{cm}^{2} \mathrm{~s}^{-1}\right)$ is the diffusional coefficient of the electroactive species, $\mathrm{A}$ is the electrode area $\left(\mathrm{cm}^{2}\right)$ and $\mathrm{C}(\mathrm{mM})$ is the concentration of the electroactive specie.

On the reaction rate study, a $2 \mathrm{mM}$ concentration and a coefficient of $3.7 \times 10^{-5} \mathrm{~cm}^{2} \mathrm{~s}^{-1}$ were used [20].

It must be considered that the quantity of (1- $\alpha) \mathbf{n}_{\mathrm{a}}$ should be known, so an approximation based on its dependence with the difference between the peak potential $\mathrm{E}_{\mathrm{p}}$ and the half peak potential $\mathrm{E}_{\mathrm{p} / 2}$ can be used. This relation is shown on Equation 2 [23,24].

$$
(1-\alpha) n_{\mathrm{a}}=47.7 \mathrm{mV} /\left(\mathrm{E}_{\mathrm{p}}-\mathrm{E}_{\mathrm{p} / 2}\right)
$$

(Equation 2)

By using Equation 2, the number of electrons (Table 2) is obtained, giving a number close to 2 , which implies that the number of transferred electrons is 2 . This value was the same for all systems, as Table 2 shows, being coherent with all investigations based on nitrite oxidation $[19,25]$, where $\mathrm{NO}_{3}^{-}$, would be the main product of this reaction [26,27].

With the objective of obtaining the information about the low step of the reaction involved on the nitrite electrooxidation, the value of Tafel slope was calculated for this reaction, as Table 2 shows.

The value of Tafel slope was $123 \mathrm{mV}$ per decade for S2-CoPc system, which implies that the determinant step of the reactions is a first electronic transfer, as well as for S2-NiPc.

On S2-FePc system is no possible to determine the slow step of the reaction due to its slope value $(200 \mathrm{mv} / \mathrm{dec})$, which is far from pre-established values, due to diffusion on the film. So, it is possible to say that the mechanism for nitrite oxidation would be similar compared to bibliographic sources [22].
Table 2. Electrochemical calculations for $\mathrm{S} 2-\mathrm{MxPc}$ modified electrodes in nitrite oxidation ( $2 \mathrm{mM}$ nitrite in $\mathrm{pH} 11$ phosphate buffer solution).

\begin{tabular}{|c|c|c|c|c|}
\hline S2-MxPc & $\begin{array}{c}\text { Number of } \\
\text { electrons }\end{array}$ & $\begin{array}{c}\text { Slope of } \\
\mathrm{I}_{\mathrm{pvs} .} v^{l / 2}\end{array}$ & $\begin{array}{c}\text { Tafel slope } \\
\mathrm{mV} / \text { decade }\end{array}$ & $\begin{array}{c}\text { Slope of } \\
\text { Log I vs Log V }\end{array}$ \\
\hline $\mathrm{CoPc}$ & $1.78=2$ & 198.97 & 123 & 0.48 \\
\hline $\mathrm{NiPc}$ & $1.87=2$ & 189.72 & 122.7 & 0.47 \\
\hline $\mathrm{FePc}$ & $1.80=2$ & 211.57 & 200.1 & 0.45 \\
\hline
\end{tabular}

\section{Electrochemical Impedance Spectroscopy $(E I S)$ studies}

The EIS measure was calculated toward ferrate hexacyanate couple. An electrochemical system, as the one that was studied in this work, will be represented with an equivalent circuit as shown in Figure 8, in which there is a double electric layer $\left(\mathrm{C}_{\mathrm{dl}}\right)$, a electrolyte resistance $\left(\mathrm{R}_{\mathrm{s}}\right)$, a charge transfer resistance from ferrate hexacyanate $\left(\mathrm{R}_{\mathrm{ce}}\right)$ and the Warburg element that represents the species diffusion effect.

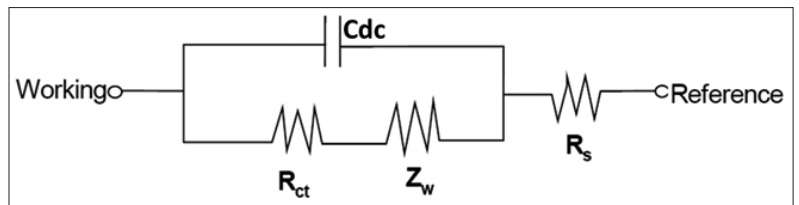

Figure 8: Equivalent circuit, where $\left(\mathrm{C}_{\mathrm{dd}}\right)$ is a double electric layer, $\left(\mathrm{R}_{\mathrm{s}}\right)$ is a electrolyte resistance, $\left(\mathrm{R}_{\mathrm{ct}}\right)$ is a charge transfer resistance from ferrate hexacyanate

Table 3 resumes the main information about the values obtained by EIS, for multilayer of monomers $\mathrm{M}-\mathrm{MxPC}$, and $\mathrm{S} 2-\mathrm{MxPC}$, as more active and stable system.

From values shown in Table 3, it is possible to extract the following information:

The resistance of the solution stays relatively constant for all systems (this feature is an intrinsic property of the solution). Also, the double layer capacitance is simulated with a constant phase element, and its exponent value, $\boldsymbol{\alpha}_{\mathrm{D}}$ is less than 1 , implying that there is a high heterogonous surface and concluding that Ms systems have a no-order tendency.

The most important issue is to discuss the variation on the $R_{\text {ct }}$ value, in which it is possible to see that, in general, the M-MxPc modified electrodes have lower values than supramolecular modifications ( $\mathrm{S} 2-\mathrm{MxPc}$ ), showing that these are more conductive surfaces. It is also important to notice that the higher values are obtained for $\mathrm{M}-\mathrm{FePc}$ and the lower ones for $\mathrm{M}-\mathrm{NiPc}$.

Finally, it must be understood that these values only give information about the film and not about catalytic activity, which would be given, exclusively, by the obtained arrange of system ( $\mathrm{S} 2-\mathrm{MxPc})$ and is no necessarily correlated to the film conductivity.

\section{CONCLUSIONS}

Two types of modified electrodes were generated which are conformed by phthalocyanines $\pi$ stacking, S1-MxPc and S2-MxPc, and which had a supremolecular role. These systems showed a higher electrochemical activity than the monomer multilayers $(\mathrm{M}-\mathrm{MxPc})$ for nitrite oxidation. The S2-MxPc electrode was the most active and the most stable compared to the S1-MxPc one. Both systems had the difference on the covalent union with the electrode surface, which allows the coordination with the complexes, forming and setting the phthalocyanine columns. With this electrode $(\mathrm{S} 2-\mathrm{MxPc})$ was possible to get a calibration curve, which had a linear response in a large range of concentrations. Electrochemical calculations were done, finding that the nitrite oxidation has a diffusional control, and occurs by the transfer of 2 electrons. Also, Tafel slopes were obtained and allowed to observe that the determinant step for $\mathrm{CoPc}$ and NiPc system is the first electronic transfer, unlike FePc where was no possible to get this information.

Through electrochemical impedance spectroscopy measurements, it was observed that the M-MxPc modified electrode has the lowest $R_{c}$ values, indicating that these are the most conductive surfaces, even though they are the less active. For this reason, the activity of the supramolecular systems (S1-MxPc and S2-MxPc) would be given, exclusively, by its supramolecular conformation, more than their activity. 
Table 3. Principal values obtained by EIS.

\begin{tabular}{|c|c|c|c|c|c|c|c|}
\hline & $\mathrm{R}_{\mathrm{s}} / \mathrm{Ohm}$ & $\mathrm{C}_{\mathrm{dc}} / \mathbf{F}$ & $\alpha_{\mathrm{DI}}$ & $\mathbf{R}_{\mathrm{ct}} / \mathrm{Ohm}$ & $\mathrm{W}_{\mathrm{R}} / \mathrm{Ohm}$ & $\mathbf{W}_{\mathrm{T}}$ & $\mathbf{W}_{\mathrm{P}}$ \\
\hline GC & 99.22 & $6.47 * 10^{-6}$ & 0.80 & 349.3 & 67253 & 216.4 & 0.5 \\
\hline M-CoPC & 88.92 & $1.25 * 10^{-6}$ & 0.68 & 426.1 & 84685 & 161.2 & 0.5 \\
\hline M-FePc & 70.04 & $1.06 * 10^{-4}$ & 0.49 & 14105 & 232430 & 171.8 & 0.5 \\
\hline M-NiPc & 67.72 & $3.60 * 10^{-6}$ & 0.83 & 225.7 & 372840 & 6870 & 0.5 \\
\hline S2-CoPc & 81.05 & $2.7 * 10^{-6}$ & 0.86 & 7534 & 72258 & 263.7 & 0.5 \\
\hline S2-FePc & 76.20 & $1.82 * 10^{-6}$ & 0.82 & 15286 & 85700 & 240 & 0.5 \\
\hline S2-NiPc & 86.75 & $2.66^{*} 10^{-6}$ & 0.85 & 4388 & 298720 & 3802 & 0.5 \\
\hline
\end{tabular}

\section{ACKNOWLEDGMENTS}

This work is dedicated to Dr. Elsa Abuin (R.I.P.), who, besides great scientist she was an excellent professor.

The authors wishes to acknowledge, project FONDECYT No 1120049 and project FONDECYT N ${ }^{\circ} 1120088$, for the financial support.

\section{REFERENCES}

1. L. F. Lindoy, "The Chemistry of Macrocyclic Ligand Complexes", Cambridge University Press, Cambridge (1989)

2. P. Bravo, F. Isaacs, G. Ramírez, F. Armijo, M. Isaacs, M. J. Aguirre, C. Zamora1, E. Trollund, J. Chil. Chem. Soc.,50, (2005), 671

3. P. Dreyse, G. Ramirez, A. Riquelme, M. Isaacs, J. Chil. Chem. Soc., 51, (2006), 923.

4. P.R. Moses, P. Wier y R.W. Murray, Anal. Chem., 47, 350 (1975)

5. Dietrich, P. Viout, J.-M. Lehn, "Macrocyclic Chemistry: Aspects of Organic and Inorganic Supramolecular Chemistry", Weinheim, New York, Basel, Cambridge: VCH (1992)

6. A. Wolf, A.E. Wasserman. Science, 15, 177 (1972)

7. N.S. Bryan. Free Radical Biol. Med., 41, 691 (2006).

8. M.I.H. Helaleh, T. Koprenage. J. Chromatogr. B, 744, 173 (2000).

9. F. Yan, E. Troncy, M. Francoueur, B. Vinet, P. Vinay, G. Czaika, G. Blaise. Clin. Chem., 43, 657 (1997).

10. [10] http://www.ispch.cl/lab_amb/met_analitico/doc/ambiente\%20pdf/
Instituto de Salud Pública de Chile, Ministro de Salud, Gobierno de Chile (2012).

11. A. Aydin, O. Ercan, S. Tascioglu, Talanta 66,1181 (2005)

12. I. Isildak, A Asan, Talanta 48,967 (1999)

13. M. Bertotti, D. Pletcher. Anal. Chim. Acta, 49, 337 (1997).

14. L. Jiang, R. Wang, X. Li, L. Jiang, G. Lu. Electrochem. Commun., 7,597 (2005).

15. C.A. Caro, F. Bedioui, J.H. Zagal. Electrochim. Acta, 47,6045 (2004)

16. A.Y. Chamdi, A.G. Fogg. Analyst, 113, 1723 (1998)

17. J.N. Barisci, G.G. Wallace. Anal. Lett., 24, 2059 (1991)

18. Yeager E. J Mol Catal 38 ,5, (1986).

19. G. Ramirez, M. Lucero, A. Riquelme, M. Villagran, J. Costamagna,E. Trollund, M.J. Aguirre, J. Coord. Chem. 57, 249 (2004)

20. E. Kimura, Prog. in Inorg. Chem., 41, 443. (1994).

21. F. Bedioui, S. Trevin, V. Albin, M.G. Gomez Villegas, J. Devynck, Anal. Chem. Acta 341,177, (1997).

22. R. Rios, A. Marín and G. Ramirez J. Coord. Chem., 63,1294, (2010).

23. Shi C, Anson FC. Inorg Chem ; $\mathbf{4 2 9 8} 305$, (1990).

24. A.J. Bard, L.R. Faulkner. Electrochemical Methods, Fundamentals and Applications, Wiley, New York (1980).

25. N.S. Trofimova, A.Y. Safronov, O. Ikeda, Electrochim. Acta $\mathbf{5 0}, 4637,(2005)$

26. K.I. Ozoemena, T. Nyokong, Talanta 67, 162 (2005).

27. K.A. Macor, T.G. Spiro, J. Am. Chem. Soc. 105, 5601, (1983) 